\title{
Treatment of lead-poisoned rats through oral administration of palm oil extracts
}

\author{
Peter Twumasi*, Kwabena Nsiah and Emmanuel Yeboah Osei \\ Department of Biochemistry and Biotechnology, Kwame Nkrumah University of Science and Technology, Kumasi, \\ Ghana.
}

Accepted 4 February, 2014

\begin{abstract}
The palm fruit (Elaies guineensis) is the source of palmitic-oleic rich semi-solid fat and fat-soluble minor components, made up of vitamin $E$ (tocopherols and tocotrienols), carotenoids and phytosterols. This study was in two parts. Firstly, it examined the effects of palm oil fractionation methods on recovery and concentration of carotenes, tocopherols and tocotrienols which are known to have nutritional and medicinal properties. Secondly, the study also investigated lead $(\mathrm{Pb})$ poisoning effects on blood of albino rats and the efficacy of treatment with crude palm oil and palm oil extracts. The extraction methods employed in the study were adsorption chromatography, saponification and bleaching. The palm fruits used were of the Tenera variety, obtained from a plantation located at Goaso in Ghana. Examination of the palm oil extracts revealed that the unsaponifiable fraction contained $19,570 \mathrm{ppm}$ carotene, $39,290 \mathrm{ppm}$ vitamin $\mathrm{E}$ (tocols), $2.7 \%$ of carotenes, and $4.6 \%$ of free fatty acids (FFA). The adsorption chromatographic isolated fraction contained $16,310 \mathrm{ppm}$ of carotenes, 19,870 ppm of tocols and $3.3 \%$ of FFA. The bleached fraction had a reduced level of carotenes and tocols with values of $209 \mathrm{ppm}$ and $640 \mathrm{ppm}$ respectively. A high FFA of 13.1\% was recorded. The crude palm oil contained $530 \mathrm{ppm}$ of carotenes, $1,040 \mathrm{ppm}$ of tocols and $4.6 \%$ of FFA. Oral administration of $2 \mathrm{~g} / \mathrm{L}$ lead acetate significantly decreased red blood cell count, haemoglobin level, haematocrit value and platelet count $\mathbf{4 0}$ days after treatment in rats, compared with the control group (that is, rats administered with deionized water). Crude palm oil and palm oil extracts administered $(0.5 \mathrm{ml} / \mathrm{kg}$ body weight/day) significantly restored the normal blood conditions of the lead-poisoned rats. However, the bleached fraction had no significant effect on the rats. The unsaponifiable matter and the adsorption chromatographic fractions reversed the poisoning effect of lead in the rats to near normal levels. The efficiency of these extracts in treating lead toxicity depended on the contents of carotenes and tocols, which are biological antioxidants. Considering oxidative stress as the major mechanism of lead toxicity, and this study has shown that the high level of antioxidants in palm oil extracts makes it effective natural product for the treatment of lead poisoning.
\end{abstract}

Key words: Antioxidant, carotene, lead poisoning, palm oil, tocopherols (tocols).

\section{INTRODUCTION}

Oil palm (Elaeis guineensis) is believed to have originated from West Africa. The commercial value of the crop lies mainly in its oil. Oil palm is unique in that it produces two types of oil. The fleshy mesocarp produces palm oil and the kernel produces palm kernel oil. Both are edible oils but with very different chemical composition, physical properties and applications (Poku, 2002).

There are three varieties of oil palm. The Dura, the main variety found in the groves, has been the main source of palm oil in Africa. The Dura has a large nut with 
a thick shell and thin mesocarp. The other variety is Pisifera. The Pisifera has a small fruit with no shell. Breeding works involving crossing the Dura and a shellless Pisifera, have led to the development of a hybrid variety called Tenera which has much thicker mesocarp containing much more oil than either of its parents. The Tenera palm kernel is smaller than the Dura kernel although the Tenera bunch is much larger than Dura. In all, the Tenera is a much better variety for industrial and economic purposes.

Palm oil is mainly made up of palmitic and oleic fatty acids which tend to be semi-solid fat at room temperature (Sundram et al., 2001). Crude palm oil possesses 1\% minor components; amongst them are carotenoids ( $\alpha$ and $\beta$ carotene), vitamin $E$ (in the form of tocotrienols and tocopherol). Crude palm oil is considered to be the richest natural source of carotenoids (about 15 times more than in carrots). The human body uses carotenoids as Vitamin A (Choo et al., 1997). Although present in small quantities, these minor constituents, to a certain extent are responsible for the healing or medicinal properties of palm oil.

Carotenoids and tocols serve as biological antioxidants necessary for protection of cells and tissues from oxidative stress (Packer et al., 2001). These natural antioxidants act as buffers against free radicals and are believed to play a protective role in cellular ageing, atherosclerosis, cancer, arthritis, and Alzheimer's disease (Goh et al., 2012; Parker, 1991).

Aside the nutritional properties, the healing properties of palm oil have been recognized for generations (Sundram, 2011). Until modern medicine arrived, red palm oil was the remedy of choice for nearly every illness in most parts of Africa (Chandrasekharan et al., 2000). When someone got sick, drinking a cupful of palm oil was a remedy of choice. Even today, many traditional healers rely upon the age-old treatment technique (Kritchevsky, 2000). Today, scientists are recognizing the value of red palm oil in the treatment and prevention of diseases. There have been a number of scientific studies that support the medicinal use of palm oil. Hornstra, (1988) in the Netherlands first demonstrated that palm oil has an anticlotting effect, and is as antithrombotic as the highly unsaturated sunflower seed oil. A human study showed that tocotrienols (from palm oil) supplementation can reduce re-stenosis of patients with carotid atherosclerosis (Goh et al., 2012). Tocopherol and its relative, tocotrienol in palm oil, inhibit human platelets from "sticking" to each other. A study conducted by Rand et al., (1988) showed that a palm oil diet either increases the production of prostacyclin which inhibits blood-clotting or decreases the formation of thromboxane which induces blood-clotting.

Chelating agents have long been used in the pharmacological treatment of lead poisoning and other heavy metal poisoning, the management of which is still a problem, particularly in developing countries. These drugs produce significant and frequent side effects, depending on their mechanisms of action which may lead to minor complications such as headache, nausea and vomiting, rashes, anaemia, nasal congestions (Tell et al., 2010), and severe complications including renal toxicity progressing to nephrotic syndrome, have been described (Tell et al., 2010). Economically, they are expensive and cannot be easily afforded by the rural poor who are mostly vulneralble to metallic poisoning. Natural products used for treatments have proven to have minimal side effects and are also cost-effective.

This study therefore aimed at producing and using various palm oil fractions for the treatment of lead poisoning in rat models.

\section{MATERIALS AND METHODS}

\section{Sample collection}

Ripened palm fruits were obtained from an oil palm plantation located at Goaso in the Brong Ahafo Region of Ghana. The Tenera variety was selected for this study.

\section{Extraction of palm oil}

A $10 \mathrm{~kg}$ freshly harvested ripe oil palm fruits were boiled in a $20 \mathrm{~L}$ pressure cooker for four hours. A pulp mass was produced by pounding the boiled fruits using wooden pestle and mortar. The pulp was immersed in $10 \mathrm{~L}$ water and stirred thoroughly. The fibres and the seeds were filtered out using a basket as a sieve. The filtrate or infusion was poured into an aluminium cooking pot and boiled for five hours. The heated mixture was allowed to cool and 2 $L$ of cold water was added to the surface by a sprinkler. The palm oil which set on top of the aqueous portion of the boiled filtrate was scooped into a fresh container. The collected oil was heated gently for ten minutes to remove traces of water.

\section{Fractionation of crude palm oil}

Three palm oil fractionation methods were employed in this study:

\section{Preparation of unsaponifiable extract}

This method was as described by Meloan, (2009) with some modifications. A $10 \mathrm{ml}$ sample of crude palm oil was placed in a 250 $\mathrm{ml}$ conical flask and $15 \mathrm{ml}$ of $20 \%$ sodium hydroxide added and stirred with the aid of a magnetic stirrer. The flask was corked and connected to a vacuum pump. The mixture was boiled on a hot plate until the solution thickened. The flask was removed from the hot plate and disconnected from the vacuum pump. Stirring continued as the solution cooled slowly. The cooled solution was transferred into a $500 \mathrm{ml}$ separatory funnel and $200 \mathrm{ml}$ of hexane was added. It was shaken and mounted on a retort stand to settle. The tap was opened to elute the bottom layer (soap). The upper layer was washed several times with distilled water until the waste water tested neutral to phenolphthalein. This upper layer was labelled as the unsaponifiable extract of palm oil. This was then stored in a cold dry place.

\section{Preparation of silica gel palm oil extract}

The method was based on the one described by Ahmad et al. (2008). A chromatographic glass tube, $3.0 \mathrm{~cm}$ in diameter, was mounted on a retort stand. A small glass wool was plugged at the 
bottom of this tube. An adsorbent, silica gel (70 to 230 mesh), was used to fill the column up to a height of $5.0 \mathrm{~cm}$. The sides of the column were tapped four times to remove air spaces. A glass rod was used to press down the adsorbent and flattened the surface. The eluting solvent consisted of $100 \mathrm{ml} \mathrm{n}$-hexane. $10 \mathrm{ml}$ of crude palm oil was dissolved in $30 \mathrm{ml}$ of $\mathrm{n}$-hexane and introduced into the column. The eluent was collected into a fresh flask until the adsorbent in the column became colourless. The collected fraction was stored in a cool, dry place to serve as the silica gel palm oil extract.

\section{Preparation of bleached palm oil extract}

Bleaching was carried out based on a method described by Patterson (1992). A mass ratio of 1 silica gel to 11 crude palm oil (CPO) was used. An amount of $110 \mathrm{~g}$ of CPO was poured into a beaker and heated on a hot plate. With the aid of a magnetic stirrer, $\mathrm{CPO}$ was stirred continuously until it reached $100^{\circ} \mathrm{C}$. Thereafter, 6 drops of phosphoric acid was added to the CPO, followed by the addition of $10 \mathrm{~g}$ silica gel. The adsorbent was added slowly to ensure a uniform mixture with the CPO and also to prevent bubble formation. The mixture was heated again for an hour until it reached $150^{\circ} \mathrm{C}$ to complete bleaching process. After bleaching was achieved, the mixture was allowed to cool. The spent adsorbent was separated from the bleached palm oil by filtration using Whatman's No. 1 filter paper. Filtration was carried out in the oven at $80^{\circ} \mathrm{C}$, for a period of $22 \mathrm{~h}$.

\section{Quantitation of carotene}

The carotene content of the crude palm oil (CPO) was determined according to the method described by Coursey (2000). $3 \mathrm{~g}$ of CPO was dissolved in $20 \mathrm{ml}$ hexane in a $50 \mathrm{ml}$ volumetric flask. A Spectrophotometer (V-1100, J.P Selectra, Spain) was used to measure the absorbance at $446 \mathrm{~nm}$. Hexane was used as the blank solution. Using the absorbances obtained, the concentration (ppm) of carotene in the sample was calculated, using the formula below;

$[$ Carotene $]=\left[\mathrm{K}_{\mathrm{Df}} \times\right.$ Absorbance $(446 \mathrm{~nm}) \times$ Volume $\left.(\mathrm{ml})\right] /[100 \times$ Sample weight $(g)]$

Where, Volume $=$ volume of hexane mixed with palm oil, $\mathrm{K}_{\mathrm{Df}}$ (diffusion coefficient) $=383$

The above procedure was repeated with other palm oil extracts.

\section{Quantitation of tocols as Vitamin E}

$0.5 \mathrm{ml}$ Crude palm oil (CPO) was dissolved in hexane in a $1.0 \mathrm{ml}$ vial. The prepared CPO-hexane mix was then injected into a high performance liquid chromatography (HPLC) system (SMI3000SE, Hitachi, Germany) with a fluorescence detector (excitation at 295 $\mathrm{nm}$ and emission at $325 \mathrm{~nm})$ and an analytical silica column $(25 \mathrm{~cm}$ $\times 4.6 \mathrm{~mm}$ ID, stainless steel, $5 \mu \mathrm{m}$ ) was used to analyse vitamin $\mathrm{E}$ content, according to the method described by $\mathrm{Ng}$ and Tan (1999). The mobile phase used was hexane: tetrahydrofuran: isopropanol $(100: 6: 4 \mathrm{v} / \mathrm{v})$ at a flow rate of $1.0 \mathrm{ml} / \mathrm{min}$. The HPLC system was calibrated using the standard vitamin E, (obtained from Merck, Germany) and the concentration (ppm) of vitamin E in CPO was determined. The procedure was repeated with other palm oil extracts. Using the results obtained the concentrations of vitamin $\mathrm{E}$ in the samples were calculated, using the following formula:

$[$ Vitamin E] $=\mathrm{A}$ sample $\times[$ STD $](\mathrm{ppm}) \times \mathrm{V}$ hex $(\mathrm{ml}) / \mathrm{A}$ STD $\times \mathrm{Wt}$ sample $(g)$

Where, $[$ STD $]=$ concentration of standard, $A$ sample $=$ area of sample, A STD = area of standard, $\mathrm{V}$ hex = volume of hexane, $\mathrm{Wt}$ sample $=$ weight of sample.

\section{Determination of free fatty acid in the palm oil extracts}

Free fatty acid (FFA) contents in the palm oil extracts were determined by titration according to the PORIM test method (1990). The palm oil samples for the analysis were melted at $60-70^{\circ} \mathrm{C}$ and $10 \mathrm{~g}$ each weighed into separate $50 \mathrm{ml}$ Erlemeyer flasks. $20 \mathrm{ml}$ ethanol and three drops of phenolphthalein were added and placed on the hot plate. The temperature was maintained at $40^{\circ} \mathrm{C}$. The flask was swirled gently while titrating with $0.1 \mathrm{M} \mathrm{NaOH}$ to the first permanent pink colour. The volume of $\mathrm{NaOH}$ used was recorded. The percentage FFA in the sample was calculated, using the formula:

$$
\text { FFA \% as palmitic acid }=\frac{25.6 \times \mathrm{M}(\mathrm{NaOH}) \times \mathrm{V}}{\mathrm{W}}
$$

Where, $\mathrm{M}=$ Molarity of $\mathrm{NaOH}$ solution, $V=$ volume of $\mathrm{NaOH}$ solution used in $\mathrm{ml}, \mathrm{W}=$ weight of sample

\section{In vivo investigation of lead detoxification by palm oil extracts in rat models}

Design and dosing of experimental animals were based on the method of Ashour (2002) with some modifications. Pre-adult male albino rats, weighing 100-120 g, obtained from the Breeding Unit of the Faculty of Pharmacy, KNUST in Kumasi were used in the study. The rats acclimatized for one week in ventilated plastic cages with wire mesh covers. The cages contained sawdust with high urine absorbing capacity. Each cage contained six rats at ambient temperature and humidity with an alternating $12 \mathrm{~h}$ light/dark cycle. Diet and water were supplied ad libitum throughout the experimental period. The feed consisted of milled dried maize and fish $(5: 1 \mathrm{~kg})$. A sublethal dose of $2 \mathrm{~g} / \mathrm{L}$ lead acetate was used. The dosage of lead acetate and palm oil were based on other studies (Flora et al., 2010; Wang and Quinn, 1999). The entire experimental treatment lasted for 40 days and it involved eight (8) treatments. The Control Group (A) was orally administered with deionized water daily for 40 days. The first experimental Group (B) was orally administered with lead acetate solution $(2 \mathrm{~g} / \mathrm{L})$ daily for 40 days. In the second experimental Group (C) of animals, lead acetate treatment lasted for 35 days followed by five (5) days of deionized water. Rats in the third experimental Group (D) were given lead acetate and crude palm oil simultaneously for the entire 40 days. The Group D was used to show the prophylactic properties of palm oil against lead poisoning. The fourth experimental Group (E) was divided into four sub-groups E1, E2, E3 and E4. Each sub-group contained six rats. Sub-group E1 was administered the lead acetate for 35 days followed by oral administration of $0.5 \mathrm{ml}$ crude palm oil per $\mathrm{kg}$ body weight per day for five days. Sub-group E2 was administered with lead acetate (2 $\mathrm{g} / \mathrm{L})$ for 35 days followed by $0.5 \mathrm{ml}$ silica gel palm oil extract per $\mathrm{kg}$ body weight per day for five days. The sub-group E3 animals, after 35 days of lead acetate treatment, were orally admi-nistered with $0.5 \mathrm{ml}$ bleached palm oil per $\mathrm{kg}$ body weight per day for the remaining five days. Finally, the sub-group E4 rats pre-treated with lead acetate for 35 days were orally treated with $0.5 \mathrm{ml}$ unsaponifiable palm oil extract per $\mathrm{kg}$ body weight per day for the remaining five days (Table 1). Lead acetate was administered through drinking water while the palm oil extracts through oral gavaging.

\section{Blood sampling and haematological analysis}

On the 40th day, animals were anesthetized and blood was taken through cardiac puncture, into two separate $10 \mathrm{ml}$ centrifuge tubes. The first tube contained EDTA and was used for complete blood count (CBC) analysis. Blood sample in the other tube without EDTA was allowed to clot. Serum was subsequently produced by centrifugation at $3000 \mathrm{rpm}$ for $20 \mathrm{~min}$ and then kept in the refrigerator at $4^{\circ} \mathrm{C}$ for analysis. Haematological parameters including red blood cells, haemoglobin, haematocrit and platelet were determined using 
Table 1. Experimental design for the administration of lead acetate, crude palm oil and palm oil extracts in male albino rats.

\begin{tabular}{|c|c|c|c|c|c|}
\hline \multirow[b]{2}{*}{ Experimental Group } & \multirow{2}{*}{$\begin{array}{c}\text { Oral } \\
\text { administration of } \\
\text { lead acetate }(2 \mathrm{~g} / \mathrm{L})\end{array}$} & \multicolumn{4}{|c|}{ Oral administration of palm oil and its extracts } \\
\hline & & $\begin{array}{l}\text { Crude palm oil } \\
\text { (CPO) }\end{array}$ & $\begin{array}{c}\text { Silica gel } \\
\text { extract }\end{array}$ & $\begin{array}{c}\text { Bleached } \\
\text { extract }\end{array}$ & $\begin{array}{l}\text { Unsaponifiable } \\
\text { palm oil extract }\end{array}$ \\
\hline A (Negative control) & - (Day 0-40) & - & - & - & - \\
\hline B (Positive control 1) & $+($ Day 0-40) & - & - & - & - \\
\hline C (Positive control 2) & $+($ Day 0-35) & - & - & - & - \\
\hline $\mathrm{D}$ & $+($ Day $0-40)$ & $+($ Day 0-40) & - & - & - \\
\hline E1 & + (Day 0-35) & $+($ Day 36-40) & - & - & - \\
\hline E2 & + (Day 0-35) & - & $+($ Day 36-40) & - & - \\
\hline E3 & $+($ Day $0-35)$ & - & - & $+($ Day 36-40) & - \\
\hline E4 & $+($ Day 0-35) & - & - & - & $+($ Day 36-40) \\
\hline
\end{tabular}

The animals in each group were treated for 40 days. The symbol (+) indicates presence of the factor and (-) represents absence of the factor under consideration.

Table 2. Concentration of carotenes and tocols in crude palm oil and palm oil extracts.

\begin{tabular}{lcccc}
\hline \multirow{2}{*}{ Phytonutrient } & \multicolumn{4}{c}{ Concentration (ppm) } \\
\cline { 2 - 5 } & Crude palm oil & Silica gel extract of palm oil & Bleached palm oil & Unsaponifiable matter of palm oil \\
\hline Carotenes & 530 & 16310 & 209 & 19570 \\
Tocols & 1040 & 19870 & 640 & 39290 \\
\hline
\end{tabular}

Table 3. Free fatty acid (FFA) content of crude palm oil and palm oil extracts.

\begin{tabular}{lc}
\hline Crude palm oil and fraction & Free fatty acid content $(\%) \mathbf{v} / \mathbf{v}$ \\
\hline Crude palm oil & 4.6 \\
Silica gel extract of palm oil & 3.3 \\
Bleached palm oil & 13.8 \\
Unsaponifiable matter of palm oil & 2.7 \\
\hline
\end{tabular}

Sysmex analyzer ((Lincolnshire, USA).

\section{Statistical analysis}

Data collected were expressed as mean values $\pm S E(n=6)$. Means of samples were compared by one-way analysis of variance (ANOVA). Significant differences between means were determined by Bonferroni's multiple comparison test $(P<0.05)$ and results presented graphically. The software used was GraphPad Prism version 4.0 (San Diego California, USA).

\section{RESULTS}

\section{Quantitation of carotene and tocol contents of palm oil and its extracts}

The unsaponifiable palm oil recorded the highest concentration of carotenes (19570 ppm) and tocols (39290 ppm). This was closely followed by silica gel extract which recorded 16310 ppm of carotenes and 19870 ppm of tocols. The bleached palm oil had the least amount of both carotenes and tocols (Table 2).

The bleached palm oil was found to contain the highest amount of free fatty acids $(13.8 \% \mathrm{v} / \mathrm{v})$ than the other palm oil extracts (Table 3 ). The crude palm oil was second highest in terms of free fatty acid content and about three times lower than bleached oil. Silica gel extract contained 3.3\% (v/v) FFA, about four times as in the bleached oil extract. The unsaponifiable matter had the least level of FFA (Table 3).

\section{Haematological analysis}

Oral administration of lead acetate solution $(2 \mathrm{~g} / \mathrm{L})$ for a period of 40 days caused very significant decrease $(P<0.01)$ in RBC count. When lead acetate was administered for 35 days, RBC count still exhibited a highly significant decrease (Figure 1). In animals orally gavaged with palm oil ( $0.5 \mathrm{ml} / \mathrm{kg}$ body weight) alongside lead acetate, a significant decrease was observed as compared to the control. The oral gavaging of crude palm oil and palm oil fractions to the 35-day long lead-poisoned rats (Groups E1, E2, E3 and E4) showed various degrees of increments in their RBC counts. The unsaponifiable palm oil extract exhibited the highest effect in restoring normal $\mathrm{RBC}$ count and the bleached palm oil with the least effect 


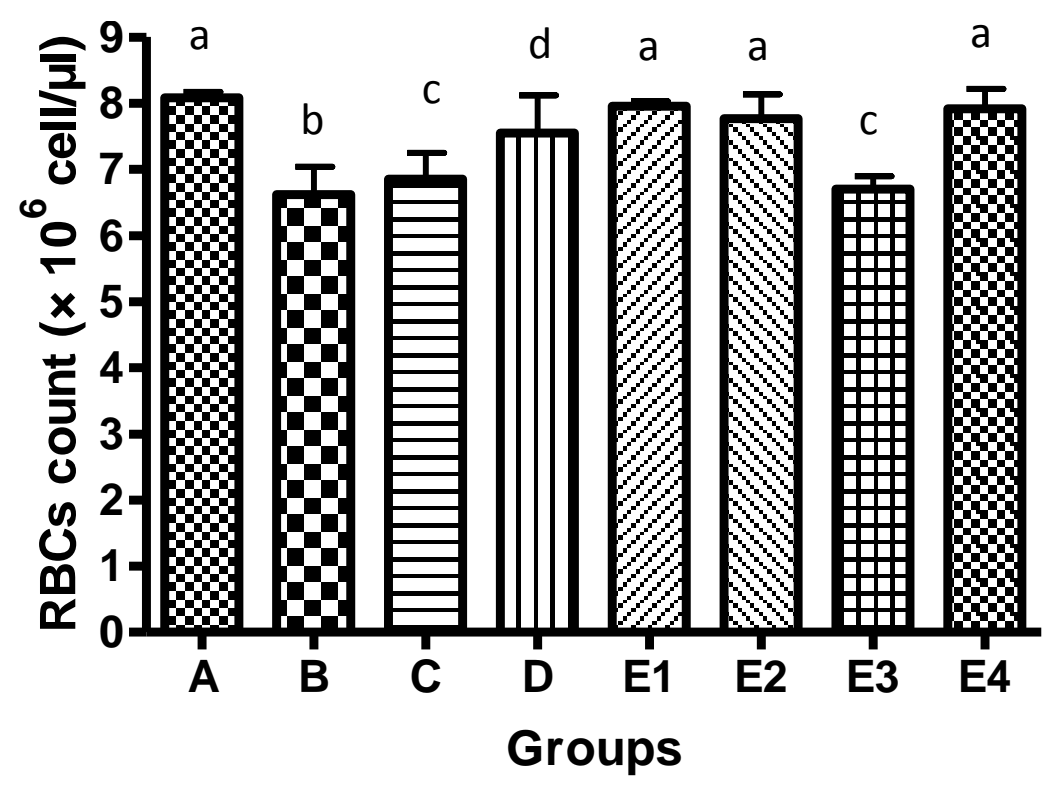

Figure 1. Effects of orally administered lead acetate $(2 \mathrm{~g} / \mathrm{L})$, crude palm oil and palm oil extracts on red blood cells count of albino rats. A (negative control), $B$ (rats given lead acetate for 40 days), $C$ (rats given lead acetate for 35 days), D (rats given lead acetate and crude palm oil), E1 (rats treated with crude palm oil after 35 days of lead poisoning), E2 (rats treated with silica gel extract after 35 days of lead poisoning), E3 (rats treated with bleached palm oil after 35 days of lead poisoning) and E4 (rats treated with unsaponifiable matter after 35 days of lead poisoning). Values are means $\pm S E(n=6)$. Bars with different letters show significant differences $(p<0.05)$.

(Figure 1).

The groups administered lead acetate $(2 \mathrm{~g} / \mathrm{L})$ for 35 days showed a significant decrease in haemoglobin content, compared to the control (Figure 2). The effect was similar in the group treated with lead acetate over the 40 day period. The groups given palm oil or palm oil fractions with the exception of those given bleached palm oil had higher haemoglobin levels. Silica gel palm oil extract and unsaponifiable palm oil extract were the most effective in restoring normal levels of haemoglobin. Bleached palm oil fraction (Group E3) produced the least effect on haemoglobin. The rats that were given lead acetate alongside palm oil (Group D) showed increase in haemoglobin content when compared with the groups that were given lead acetate only (Figure 2).

There was significant reduction in haematocrit (Hct) value when animals were given lead acetate (Figure 3). The rats in the Group C in which lead acetate was discontinued showed significant decrease in Hct value relative to the negative control Group A). Administration of palm oil and palm oil extracts to 35-day long lead-poisoned animals significantly increased Hct value over the untreated rats. The treatment with crude palm oil maintained the Hct values close to the normal level (Figure 3).

The mean values of platelet count of lead-treated rats showed significant decrease against the negative control $(P<0.05)$. The group administered with crude palm oil and lead acetate simultaneously showed significant decrease in the platelet count compared to the negative control (Group A). The rats given crude palm oil and palm oil extracts recorded platelet counts close to the normal levels. With the exception of bleached palm oil extract, all the palm oil fractions significantly restored the platelet count in the lead-poisoned rats.

\section{DISCUSSION}

The present study has shown that saponification and adsorption chromatography are good techniques for concentrating tocols and carotene contents of palm oil. The palm oil fractionation techniques employed in the study successfully produced palm oil extracts containing nearly ten times (10x) tocols and carotene as found in the crude palm oil. The amounts of phytonutrient in palm oil were studied by Choo et al. (1997). Earlier studies have established crude palm oil to contain nearly $1 \%$ minor components made up of phytonutrients among which include carotenoids, tocopherols and tocotrienols and sterols. Thermal bleaching on the contrary, led to significant reductions in the levels of the phytonutrienents in palm oil (Table 2). This could be due to instability of tocols and carotene to heat (Borner et al., 2009).

The free fatty acid (FFA) analysis of the crude palm oil and purified extracts showed direct correlation between temperature and FFA during the thermal bleaching process. FFA liberation from the parent structure, triglyceride, 
a

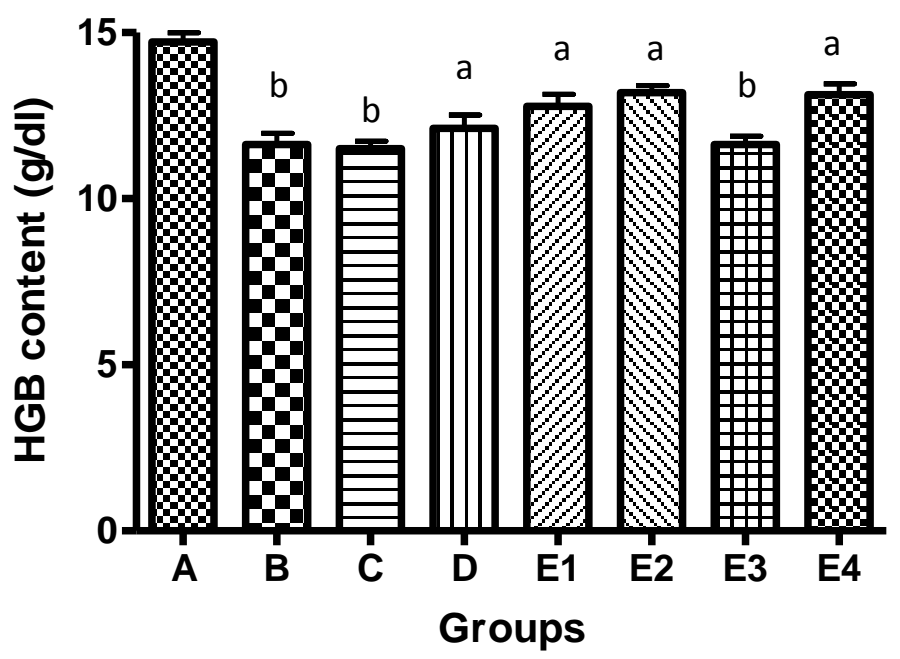

Figure 2. Effects of orally administered lead acetate (2 g/L), crude palm oil and palm oil extracts on haemoglobin content of albino rats. A (negative control), B (rats given lead acetate for 40 days), C (rats given lead acetate for 35 days), D (rats given lead acetate and crude palm oil), E1 (rats treated with crude palm oil after 35 days of lead poisoning), E2 (rats treated with silica gel extract after 35 days of lead poisoning), E3 (rats treated with bleached palm oil after 35 days of lead poisoning) and E4 (rats treated with unsaponifiable matter after 35 days of lead poisoning). Values are means \pm SE $(n=6)$. Bars with different letters show significant differences $(p<0.05)$.

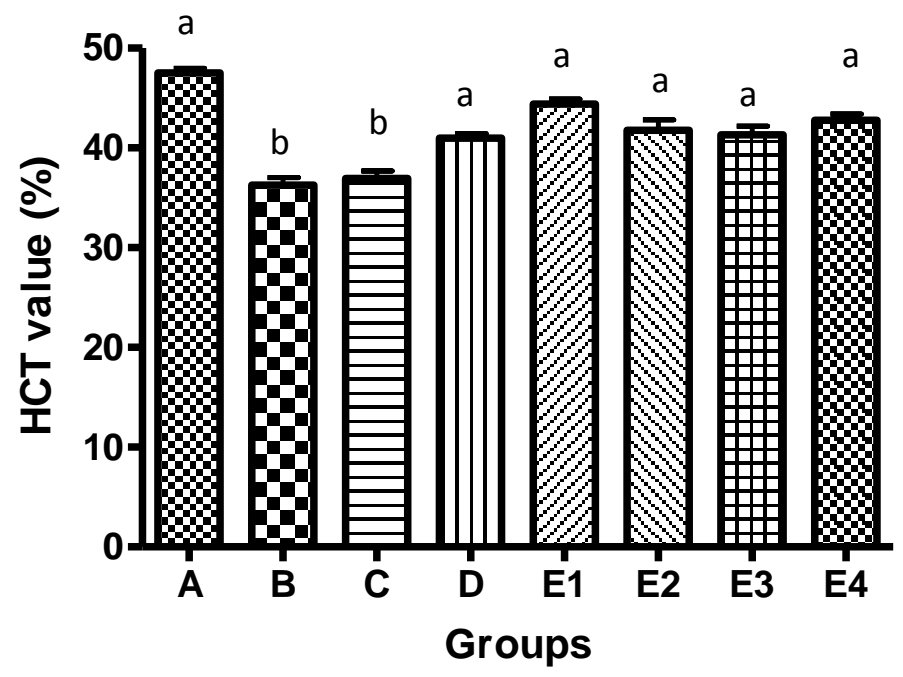

Figure 3. Effects of orally administered lead acetate $(2 \mathrm{~g} / \mathrm{L})$, crude palm oil and palm oil extracts on blood haematocrit value of albino rats. A (negative control), B (rats given lead acetate for 40 days), C (rats given lead acetate for 35 days), D (rats given lead acetate and crude palm oil), E1 (rats treated with crude palm oil after 35 days of lead poisoning), E2 (rats treated with silica gel extract after 35 days of lead poisoning), E3 (rats treated with bleached palm oil after 35 days of lead poisoning) and E4 (rats treated with unsaponifiable matter after 35 days of lead poisoning). Values are means \pm SE $(n=6)$. Bars with different letters show significant differences $(p<$ 0.05). 


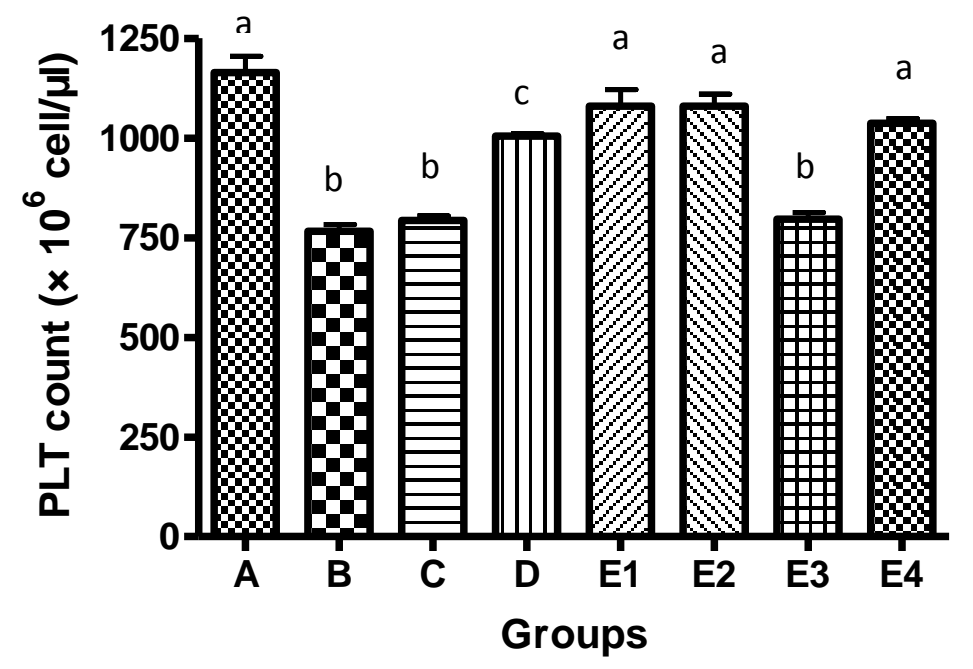

Figure 4. Effects of orally administered lead acetate $(2 \mathrm{~g} / \mathrm{L})$, crude palm oil and palm oil extracts on blood platelet count of albino rats. A (negative control), B (rats given lead acetate for 40 days), $C$ (rats given lead acetate for 35 days), D (rats given lead acetate and crude palm oil), E1 (rats treated with crude palm oil after 35 days of lead poisoning), E2 (rats treated with silica gel extract after 35 days of lead poisoning), E3 (rats treated with bleached palm oil after 35 days of lead poisoning) and E4 (rats treated with unsaponifiable matter after 35 days of lead poisoning). Values are means \pm SE $(n=6)$. Bars not sharing common letters are significantly different $(p<0.05)$.

occurs in a process characterized by high temperature and other hydrolytic solvents (Siew, 2011). The bleached palm oil contained $13.8 \%$ (v/v) FFA, an amount nearly $300 \%$ of what is found in the crude palm oil. Conversely, thermal bleaching of palm oil reduces carotene and tocol contents. Fractionation using saponification and adsorption chromatography produced extracts with reduced levels of FFA. Saponification and adsorption chromatography produced opposite effect - thus high concentrations of carotene and tocols, and reduced FFA content.

When $2 \mathrm{~g} / \mathrm{L}$ of lead acetate was orally administered for 40 days, there was a highly significant increase in blood lead levels (BLL). Earlier studies have shown time-anddose dependency of blood lead levels (Flora et al., 2010). In the second part of the present study, the effects of oral administration of lead acetate $(2 \mathrm{~g} / \mathrm{L})$ on haematology of male rats weighing 100-120 g were determined. The current study shows oral administration of $2 \mathrm{~g} / \mathrm{L}$ lead acetate to male albino rats for a period of $35-40$ days to be effective in inducing haematological impairments or insults. The lead dose administered is comparable to amounts found in common sources of lead in domestic and industrial settings such as paint, crayon, pencils, chalks and some clay.

The lead-poisoned rats showed significant decreases in their RBC count (Figure 1). Patrick (2006) earlier reported in a study that erythrocytes have high affinity for lead, binding $99 \%$ of the lead in the bloodstream. Lead destabilizes the plasma membranes resulting in the decrease in RBC fluidity and subsequently increased erythrocytes haemolysis (Philip and Gerson, 2012).

The results establish RBC count (Figure 1), haemoglobin content (Figure 2), haemotocrit value (Figure 3) and platelet count (Figure 4) to be significantly decreased in rats exposed to lead acetate. Lead interferes with haemoglobin synthesis. Specifically, lead inhibits aminolevulinic acid dehydratase (ALAD) enzyme (Ellenhorn, 2012) which is critical enzyme in the biosynthetic pathway of haem (Farrant and Wigfield, 1998). The decrease in haematocrit and platelets counts result from leadinduced anaemia through haem biosynthesis and reduced life span of the RBC (Gurer-Orhan, 2008).

Treatment of the lead-poisoned rats by oral administration of various doses of crude palm oil and the three palm oil extracts showed significant recovery indicated by RBC count, haemoglobin concentration, haematocrit and platelet count (Figures 1-4). The prophylactic effect of palm oil on lead-poisoned rats, characterized by the improvement of haematological indices has been reliably shown by this study. The two palm oil extracts, unsaponifiable matter fraction and silica gel extract, contained high amounts of phytonutrients composed mainly of carotenes, tocopherols and tocotrienols. These properties made the two extracts more effective in alleviating the lead toxicity in the animals.

The two palm oil extracts independently reversed haematological effects of lead poisoning to near normal levels. Crude palm oil, though not as effective as the unsa- 
ponifiable and silica gel palm oil extracts, was also effective in detoxifying lead poisoning in the rats. Antioxidant properties of tocols and carotenes have long been established (Packer et al., 2001; Brian, 1991). Thus the high efficacy of the silica gel and unsaponifiable extracts and to a lesser extent the crude palm oil might be due to anti-oxidation capacity of carotenes and tocols. The bleached palm oil, with trace amounts of carotenes and tocols had no significant effect on the haematological indices of lead-poisoned rats (Figures 1-4).

Oxidative stress generated by reactive oxygen species (ROS) and the depletion of antioxidant reserves is the dominant and logical mechanism for the lead toxicity (Ercal et al., 2001). Palm oil has been shown to elevate blood levels of antioxidant enzymes such as superoxide dismutase (SOD), catalase and glutathione peroxidase (lan et al., 2005). It can therefore be suggested that antioxidant action of crude palm oil and palm oil extracts might play a role in the treatment of lead poisoning. Other mechanisms of action such as chelation of the lead ion $\left(\mathrm{Pb}^{2+}\right)$ and enhanced excretion of the metal ion caused by carotenes and tocols could be important in the body's detoxification of lead (Hsu, 2011).

\section{CONCLUSIONS}

Palm oil extracts derived from saponification and silica gel chromatography contained high amounts of tocols and carotenes. The levels ranged from 19 to 38 times that of the crude palm oil. The thermal bleached palm oil extract contained trace amounts of tocols and carotenes than that in the crude palm oil. Oral administration of various doses of unsaponifiable matter and silica gel extract of palm oil at different treatment times significantly reversed abnormal haematological indices in leadpoisoned rats. The bleached palm oil extract, on the other hand, was ineffective in treating lead poisoning in the affected rats.

\section{ACKNOWLEDGEMENTS}

We acknowledge the immense contribution of the following laboratory staff of the Kwame Nkrumah University of Science and Technology: Mr. Thomas Ansah, a technician of the Department of Pharmacology, Faculty of Pharmacy; Mr. Frank Bonsu Agyeman and Mr. William Appau, technicians, and Mr. Benjamin Afful, a research assistant of the Clinical Analysis Laboratory (CAnLab) and Aflatoxin Laboratory of the Department of Biochemistry and Biotechnology.

\section{REFERENCES}

Ahmad AL, Chan CY, Abd-Shukor SR, Mashitah MD (2008). Recovery of oil and carotenes from palm oil mill effluent (POME). Chem. Eng. J. 141: 383-386.
Ashour A (2002). Can garlic lobes, olive oil or black seed oil offer protection for some serum biochemical constituents against lead toxicity in rabbits? Al-Aqsa Univ. J. 6: 74-95.

Borner G, Hollien J, Schneider M (2009). Latest Development of Cost Savings for Bleaching Process. Proceedings of the PIPOC 2009 International Palm Oil Congress (Chemistry and Technology).pp. 136-148

Brian D (1991). Carotenoid metabolism as a preparation for function. Pure Appl. Chem. 63(1):131-140.

Chandrasekharan N, Sundram K, Basiron Y (2000). Changing nutritional and health perspectives on palm oil. Brunei Int. Med. J. 2: 417427.

Choo YM, Ma AN, Yap SC (1997). Carotenes, vitamin E and sterols in oils from Elaies guineensis, Elaies oleifera and their hybrids. Palm Oil Dev. 27:1-9.

Coursey DG (2000). The Deterioration of Palm Oil during Storage. J. West Afr. Sci. Assoc. 7:101-122.

Ellenhorn MJ (2012). Lead. In: Ellenhorn MJ, ed. Ellenhorn's Medical Toxicology: Diagnosis and Treatment of Human Poisoning. 2nd ed. Baltimore, Md: Williams \& Wilkins. pp. 1564-1579.

Ercal N, Gurer-Orhan H, Aykin-Burns N (2001). Toxic metals and oxidative stress. Part 1. Mechanisms involved in metal-induced oxidative damage. Curr. Top. Med. Chem. 1:529-539.

Farrant JP, Wigfield DC (1998). Biomonitoring lead exposure with deltaaminolevulinate dehydratase (ALA-D) activity ratios. Int. Arch. Occup. Environ. Health 51:15-24.

Flora SJ, Jain VK, Behari JR, Tandon SK (2010). Protective role of trace metals in lead intoxication. Toxicol. Lett. 13:52-56.

Goh SH, Loh TP, Huang JM, Choo YM, Hew NF (2012). Antioxidants in palm oil: their chemistry and some insights from feeding experiments on rabbits. In: Ong ASH, Packer L, eds. Biological oxidants and antioxidants: molecular mechanisms and health effects. Champaign, III, USA: American Oil Chemists Society, 274-83.

Gurer-Orhan H, Sabir HU, Ozgunes H (2008). Correlation between clinical indicators of lead poisoning and oxidative stress parameters in controls and leadexposed workers. Toxicology 195:147-154.

Hornstra G (1988). Dietary lipids and cardiovascular disease: effects of palm oil. Oleagineux 43:75-81.

Hsu PC, Hsu CC, Liu MY (2011). Lead-induced changes in spermatozoa function and metabolism. J. Toxicol. Environ. Health A 55:4564.

Ian WB, Anne KK, Vladimir ML, Elena VB, Mark JF, James AB, Keith SW, Anthony JW (2005). Structures of two superoxide dismutases from Bacillus anthracis reveal a novel active centre. Acta Crystallogr. F. 61: 621-624.

Kritchevsky D (2000). Impact of red palm oil on human nutrition and health. Food Nutr. Bull. 21:182-8.

Meloan CE (2009). Chemical separations: principles, techniques and experiments. John Wiley and Sons, New York. pp. 23-34.

$\mathrm{Ng} \mathrm{JH}$, Tan B (1999). Analysis of palm oil carotenoids by HPLC with diode-array detection. J. Chromatogr. Sci. 26: 463-469.

Palm Oil Research Institute of Malaysia (PORIM) Test Methods, (1990). Palm Oil Research Institute of Malaysia. Ministry of Primary Industries, Kuala Lumpur. Malaysia palm oil. Adv. Oil Palm Res. 12:122-128.

Packer L, Weber SU, Rimbach G (2001). Molecular aspects of alphatocotrienol and antioxidant action and cell signalling. J. Nutr. 131 (2): 369S-73S.

Parker $L$ (1991). Protective role of vitamin E in biological systems. Am. J. Clin. Nutr. 53:1050S-1055S.

Patrick L (2006). Lead toxicity, a review of the literature. Part I. Exposure, evaluation, and treatment. Altern. Med. Rev. 11:2-22.

Patterson HWB (1992). Bleaching and Purifying Fats and Oils. Theory and Practice. AOCS Press, Kualar Lumpur. pp. 45-65.

Philip AT, Gerson B (2012). Lead poisoning-Part I. Incidence, etiology, and toxicokinetics. Clin. Lab. Med. 14(2): 423-44.

Poku K (2002). "Origin of oil palm". Small-Scale Palm Oil Processing in Africa. FAO Agricultural Services Bulletin 148. Food and Agriculture Organization. pp. 56.

Rand ML, Hennissen AA, Hornstra G (1988). Effect of dietary palm oil on arterial thrombosis, platelet response and platelet membrane fluidity in rats. Lipids 23(11):1019-23. 
Siew WL (2011). Characteristics of palm olein from Elaeis guineensis palm oil. Kuala Lumpur, Malaysia: Malaysian Palm Oil Board, MPOB Technology No. 23.

Sundram K (2011). Modulation of human lipids and lipoproteins by dietary palm oil and palm olein: a review. Asia Pac. J. Clin. Nutr. 6(1):12-16.
Sundram K, Sambanthamurthi R, Tan YA (2001). Nutraceuticals: Facts and fiction. Phytochemistry 68:2986-3008.

Tell I, Somervaille LJ, Nilsson U (2010). Chelated lead and bone lead. Scand. J. Work Environ. Health 18: 113-119. 